\title{
Evolving a climate-resilient electricity infrastructure in the Netherlands
}

\author{
L. Andrew Bollinger ${ }^{a^{*}}$ \\ Gerard P.J. Dijkema ${ }^{a}$ \\ Igor Nikolic ${ }^{\mathrm{a}}$
}

\begin{abstract}
A resilient electricity infrastructure is one which preserves continuity of service despite perturbations in its environment, if it fails, it does so gracefully, not catastrophically. Electricity infrastructures globally are undergoing a low-carbon transition with a yet-to-be defined endpoint. What will be the impact of these transitions on network resilience? How can we steer them to foster resilience? This paper introduces results from a model exploring the evolution of the Dutch electricity transmission network under various transition scenarios. The model captures the development of this network as a result of the decisions of a set of boundedly rational agents, representing power producers and a grid operator. These agents make repeated decisions to (dis)invest in various types of infrastructure components, driving the evolution of the network. Using network analysis techniques, we evaluate the resilience of the resulting network topologies and identify key drivers of resilience
\end{abstract}

\section{Key words: Electricity infrastructure; Climate change; Vulnerability; Simulation, Energy transitions.}

\section{Introduction}

Electricity infrastructures are complex globe-spanning socio-technical systems whose functionality depends on a relatively stable set of environmental conditions. As forcefully demonstrated by events such as the 2012 blackouts in India (620 million people without power) and Hurricane Sandy (8.5 million people without power), fluctuations in these conditions whether in the form of droughts, hurricanes or floods - can spark disturbances with potentially devastating consequences. Insofar as climate change is anticipated to affect the frequency and severity of weather extremes, it poses a potential threat to our electricity infrastructures, from degrading their integrity and performance to inciting major blackouts.

Next to the emerging issue of electricity infrastructure vulnerability to climate change, unabating societal concerns about the broader consequences of a changing climate are driving a gradual shift in the global power sector from a reliance on fossil to renewable energy sources and from carbon-intensive to low-carbon technologies. Further fueled by the privatization and

${ }^{\text {a }}$ Faculty of Technology, Policy \& Management, Delft University of Technology, 2600 GA Delft, The Netherlands

*Corresponding author: Andrew Bollinger L.A.Bollinger@tudelft.nl http://dx.doi.org/10.14453/isngi2013.proc. 6 
vertical de-integration of the electricity supply chain ${ }^{1,2,3}$, and by technological developments in the areas of renewable and distributed electricity generation, this transition will have far-reaching and systemic impacts on the infrastructure as a whole $\left.{ }^{4,5,6}\right)$. How will a low-carbon transition affect the vulnerability of our electricity infrastructures to climate change, and how can we support the development of a climate-resilient electricity infrastructure?

The vulnerability of electricity infrastructures to climate change is influenced by both the geographical configuration and topological structure of these systems. Systems with a large proportion of key components situated in heavily exposed areas will likely be more vulnerable to weather extremes, and structurally fragile systems will be more prone to amplify local disturbances into network-wide blackouts. In this paper, we explore (1) the consequences of various trajectories for a low-carbon transition on the geographical and topological features of an electricity infrastructure, and (2) the relationship between these features and the vulnerability of the infrastructure to certain types of extreme weather events that are anticipated to occur with increasing frequency as a result of climate change.

This paper introduces preliminary results from a model assessing the vulnerability of the Dutch electricity infrastructure to climate change, taking into account the various possible development trajectories of the infrastructure over the coming decades. As a low-lying coastal country located at the mouth of three major European rivers, the Netherlands is particularly exposed to sea level rise and riverine flooding, as well as to wind storm losses and extreme windspeeds ${ }^{7}$ - all of which may significantly affect the performance of infrastructure components. Moreover, the Dutch government has committed itself to a $20 \%$ reduction in carbon emissions by 2020 and an $80 \%$ reduction by 2050 . Meeting these targets will necessitate a largescale shift towards renewable and other low-carbon generation technologies and the realization of a transmission/distribution system capable of seamlessly integrating these technologies and continuously balancing supply and demand. While it is clear that a transition is necessary, we do not know precisely what form the future infrastructure will take.

\section{Positioning of the research}

A growing body of research suggests that climate change is likely to influence the supply, demand, transmission and distribution of electricity in myriad ways. Increases in mean air and water temperatures and decreases in river flows are likely to affect the availability and efficiency of thermal and hydropower generators ${ }^{8,9,10}$. Growth in the frequency and severity of windstorms may increase the occurrence of downed overhead lines, and rising sea levels combined with increased frequencies of extreme rain events may lead to periodic flooding of low-lying areas and subsequent disruption of power substations. Higher average and extreme temperatures may increase demand for air conditioning and refrigeration, possibly leading to long-term increases in peak electricity loads ${ }^{11,12}$.

While a significant body of research has elaborated on various weather/climate sensitivities of electricity infrastructure components, less is known about the vulnerability of infrastructure networks as a whole. To address this gap, our work builds on research in the area of structural vulnerability analysis of power networks. Central to this body of research is the notion of power systems as complex networks in which failures may propagate nonlinearly through the network, 
leading to critical thresholds in system performance. Beginning with a graph representation of an abstract or real-world power network, studies in this area assess how the successive removal of nodes/edges affects network performance ${ }^{13,14,15,16,17}$. This technique provides insight into patterns of degradation in system performance resulting from successive component failures.

In addressing the issue of electricity infrastructure vulnerability to climate change, we extend on this core approach of structural vulnerability analysis in several ways. First, we modify the sequence of node/edge removal so as to reflect component sensitivities to certain types of extreme weather conditions, specifically floods and windstorms. In this manner, we seek to capture extreme weather-induced patterns of network degradation, producing insight into the performance of the network under such conditions. Second, we test not a single network, but multiple networks representing different development trajectories of the Dutch electricity infrastructure. These networks reflect a range of possible futures, and are intended to capture uncertainties concerning the endpoint of a low-carbon transition.

\section{Approach}

The purpose of the model described here is to assess the vulnerability of the Dutch electricity infrastructure to climate change, and to identify options for supporting the development of a climate-resilient electricity infrastructure. The model is composed of two submodels - a model of infrastructure evolution and a model of infrastructure performance. The infrastructure evolution submodel captures the long-term development of the Dutch electricity infrastructure under various scenarios, while the infrastructure performance submodel assesses the climate vulnerability of these "evolved" infrastructures.

Infrastructure evolution submodel: The starting point for the infrastructure evolution submodel is a dataset describing the current configuration of the Dutch electricity infrastructure, including generation and transmission/distribution. Four scenarios (plus a baseline) are used to describe the development of the generation portfolio over a period of 40 years. These scenarios (Table 1) have been selected to reflect a range of possible development trajectories for the Dutch generation portfolio.

\begin{tabular}{|l|l|}
\hline \multicolumn{1}{|c|}{ Scenario } & \multicolumn{1}{c|}{ Description } \\
\hline $\begin{array}{l}\text { Centralized } \\
\text { generation }\end{array}$ & $\begin{array}{l}\text { Continued growth in large, centralized, fossil-based generation facilities. } \\
\text { Geographical consolidation of generation. }\end{array}$ \\
\hline $\begin{array}{l}\text { Distributed } \\
\text { generation }\end{array}$ & $\begin{array}{l}\text { Rapid expansion of renewables-based distributed generation, spread evenly } \\
\text { across distribution grids. Commensurate growth in centralized generation to } \\
\text { compensate for renewables intermittency. }\end{array}$ \\
\hline $\begin{array}{l}\text { Offshore } \\
\text { wind }\end{array}$ & $\begin{array}{l}\text { Rapid expansion of offshore wind in predefined North Sea locations. } \\
\text { Commensurate growth in centralized fossil-based generation to compensate } \\
\text { for intermittency. }\end{array}$ \\
\hline Import & $\begin{array}{l}\text { Gradual flattening in the growth of domestic supply, compensated by an } \\
\text { increase in supply by neighboring countries }\end{array}$ \\
\hline Baseline & Infrastructure remains unchanged from its current state. \\
\hline
\end{tabular}




\section{Table 1. Supply scenarios for the infrastructure evolution submodel}

The core of the infrastructure evolution model is an algorithm representing the decision making procedures of the Dutch transmission system operator (TSO) with respect to investments in new transmission capacity. Design criteria for the real-world Dutch transmission grid are laid out in the so-called Grid Code ${ }^{18}$, established by the Dutch Electricity Act of 1998. To ensure compliance with these criteria, the Dutch TSO carries out annual evaluations of the transmission grid $^{19}$. These analyses serve as a basis for the determination of necessary capacity upgrades. A simplified version of the TSO's assessment procedure guides capacity upgrades of transmission system components in the infrastructure evolution submodel. Each timestep during the course of a simulation (one timestep $=$ one year), an algorithm performs a set of contingency analyses under peak demand conditions for a set of four scenarios with varying geographical distributions of generation dispatch and imports/exports. As a result of these analyses, necessary capacity investments are initialized to keep the system in line with the requirements of the Dutch Grid Code.

Infrastructure performance submodel: The infrastructure performance submodel assesses the performance of the Dutch electricity infrastructure under various types of extreme weather conditions that may be expected to occur with increasing frequency as a consequence of climate change. This assessment takes the form of a structural vulnerability analysis modified to reflect certain effects of these extreme weather conditions. For each of the topologies generated by the infrastructure evolution submodel - one for each scenario representing the final (2050) state of the infrastructure - the model executes two analyses. The first analysis involves the successive removal of random power lines, with the removal of each line followed by an assessment of network performance. The second analysis involves the successive removal of substations, also followed in each case by a performance assessment. Network performance is defined as the ratio of power delivered to power demanded. In calculating network performance, the model takes into account the possibility for cascading failures, which are an important aspect of power system vulnerability, and have played a role in some of the most notorious blackouts in recent years $^{20,21}$.

The model captures the vulnerability of infrastructure components to two types of extreme weather conditions - flood events and windstorms. We have chosen to incorporate vulnerabilities to these types of extreme weather conditions given both their anticipated role in the context of climate change $e^{22,23,24}$ and their potential to affect power system performance. Vulnerabilities of infrastructure components to both floods and windstorms are represented by adjusting the probability of component failure in the structural vulnerability analysis. In the case of flood events, the probability of substation failure depends on the elevation of the substation, and in the case of windstorms, the probability of line failure is proportional to line length. Failure probabilities do not currently account for adaptation measures such as dikes or pylon designs that may provide added protection to certain components.

\section{Key Results}

Figure 1 illustrates key results from the infrastructure performance model, based on the averaged results of 100 simulation runs. In the tests of both flood and windstorm vulnerability, 
important differences can be seen in the patterns of performance degradation across the tested scenarios. In the windstorm analysis, the networks in most scenarios exhibit convex performance degradation - a sharp initial drop in performance followed by decelerating degradation with further failures. This pattern can be attributed largely to the centralized nature of production in these scenarios - by 2050 most supply is situated in a handful of coastal areas, resulting in a situation in which the failure of a few key lines can significantly cripple system performance.

The distributed generation scenario produces a very different result. In this case, the network exhibits slightly concave performance degradation, which can be attributed both to the decentralized nature of production and to the greater capacity of lines relative to the centralized and import scenarios. The decentralized nature of production means fewer "critical" lines whose failure engenders a plummet in system performance. Greater line capacities mean fewer failure cascades, since remaining lines are able to better handle the extra burdens of successive line failures.
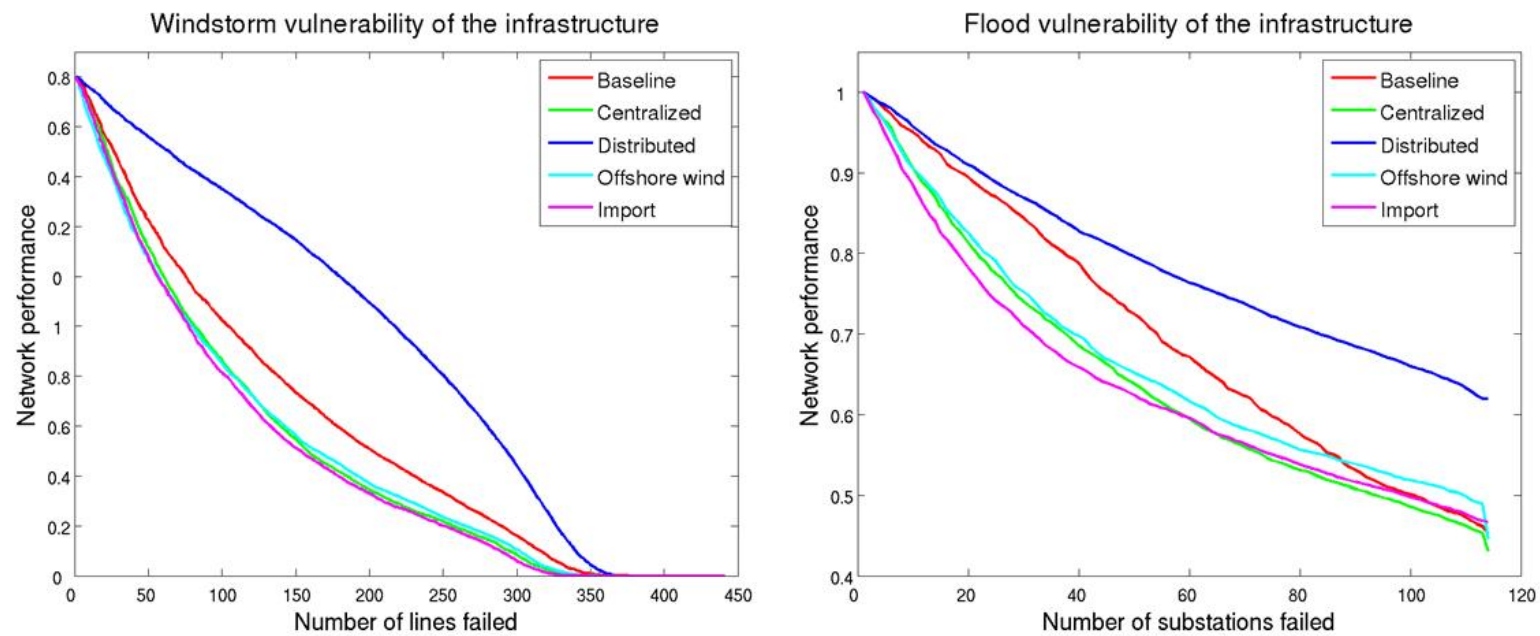

Figure 1. Windstorm and flood vulnerability for the different scenarios, based on the results of the infrastructure performance model.

The flood performance analysis exhibits similar behavior. In this case, we see a maximum performance degradation of 50-60\% in the centralized, import and offshore wind scenarios, resulting from the successive failure of 114 substations situated less than one meter above sea level. The distributed generation scenario performs better, with less than a $40 \%$ drop in performance under similar conditions. It is important to note that the smoothness of these averaged results conceals highly nonlinear behavior that may occur in individual runs. In some cases the failure of a single line or substation can cause a drop in network performance of 10$20 \%$ as the network reaches a critical threshold. These critical thresholds may be reached sooner or later, depending on the sequence in which lines or substations fail.

\section{Discussion and Conclusions}

The results suggest that a future Dutch infrastructure based around distributed generation may help to mitigate electricity infrastructure vulnerability to climate change. However, this does not 
imply that a system based around more centralized generation is inevitably less resilient. The results suggest that much degradation in system performance arises from sudden and periodic large drops in network performance when the system reaches a critical threshold. Adaptation measures such as demand-side management and generation redispatch - which have been excluded from this analysis - could be employed in real time to alleviate stress within the network as these thresholds are approached. Harder measures such as dikes and pylon reinforcements can also help to inhibit the buildup of component failures. Future research will explore the potential benefits of such options and will explore the consequences of key assumptions underlying the presented model.

\section{References}

${ }^{1}$ Markard, J., and Truffer, B., "Innovation processes in large technical systems: Market liberalization as a driver for radical change?", Research Policy, Vol. 35, Iss, 5, 2006, pp. 609-625. http://dx.doi.org/10.1016/j.respol.2006.02.008

${ }^{2}$ van Damme, E., "Liberalizing the Dutch electricity market: 1998-2004", TILEC Discussion Papers, Tilburg University, 2005.

${ }^{3}$ de Vries, L., Jong, H.D., de Bruijne, M., Glavitsch, H., and Knops, H., "Critical infrastructures at risk: Securing the European electric power system", Gheorghe, A.V., Masera, M., Weijnen, M., \& de Vries, L. (Editors), Liberalisation and internationalisation of the European electricity supply system, Dordrecht: Springer, 2006, pp. 37-84.

${ }^{4}$ Chappin, E., Stimulating Energy Transitions, PhD thesis, Delft University of Technology, 2011.

${ }^{5}$ Perelman, L., "Speculations on the transition to sustainable energy", Ethics, Vol. 90, no. 3, 1980, pp. 392 - 416. http://dx.doi.org/10.1086/292170

${ }^{6}$ Verbong, G., and Geels, F., "The ongoing energy transition: Lessons from a socio-technical, multi- level analysis of the Dutch electricity system", Energy Policy, Vol. 35, 2007, pp. 1025-1037. http://dx.doi.org/10.1016/j.enpol.2006.02.010

${ }^{7}$ Donat, M., Leckebusch, G., Wild, S., and Ulbrich, U., "Future changes in European winter storm losses and extreme wind speeds inferred from GCM and RCM multi-model simulations", Natural Hazards and Earth System Sciences, Vol. 11, 2011 pp. 1351 - 1370. http://dx.doi.org/10.5194/nhess-11-1351-2011

${ }^{8}$ Koch, H., and Vogele, S., "Dynamic modeling of water demand water availability and adaptation strategies for power plants to global change", Ecological Economics, Vol. 68, 2009, pp. 2031 - 2039. http://dx.doi.org/10.1016/j.ecolecon.2009.02.015

${ }^{9}$ Linnerud, K. Mideksa, T., and Eskeland, G., "The impact of climate change on nuclear power supply”, Energy Journal, Vol. 32, 2011, pp. 149 - 168. http://dx.doi.org/10.5547/ISSN01956574-EJ-Vol32-No1-6

${ }^{10}$ Mideksa, T., and Kallbekken, S., "The impact of climate change on the electricity market - a review", Energy Policy, Vol. 38, 2010, pp. 3579 - 3585. http://dx.doi.org/10.1016/j.enpol.2010.02.035

${ }^{11}$ Petrick, S., Rehdanz, K., and Tol, R., "The impact of temperature changes on residential energy consumption", Kiel Working Papers. Kiel Institute for the World Economy, 2010.

${ }^{12}$ Rothstein, B., Schroedter-Homscheidt, M., Haefner, C., Bernhardt, S., and Mimler, S., "Impacts of climate change on the electricity sector and possible adaptation measures", B. 
Hansjuergens \& R. Antes (Editors), Economics and Management of Climate Change, New York: Springer, 2008, pp. $231-241$.

${ }^{13}$ Albert, R., Albert, I., and Nakarado, G., ,Structural vulnerability of the North American power grid", Physics Review E, Vol. 69, 2004, pp. 1-4. http://dx.doi.org/10.1103/PhysRevE.69.025103

${ }^{14}$ Chen, G., Dong, Z., Hill, D., and Zhang, G., "An improved model for structural vulnerability analysis of power networks", Physica A: Statistical Mechanics and its Applications, Vol. 388, Iss. 19, 2009, pp. 4259-4266.

${ }^{15}$ Holmgren, A.J., "Using graph models to analyze the vulnerability of electric power networks", Risk Analysis, vol. 26, 2006, pp. 955 - 969. http://dx.doi.org/10.1111/j.1539-6924.2006.00791.x

${ }^{16}$ Rosas-Casals, M., Valverde, S., and Sole, R., "Topological vulnerability of the European power grid under errors and attacks", International Journal of Bifurcation and Chaos, Vol. 17, Iss. 7, 2007, p. 2465. http://dx.doi.org/10.1142/S0218127407018531

${ }^{17}$ Wang, J.W., and Rong, L.L., "Cascade-based attack vulnerability on the US power grid", Safety Science, Vol. 47, 2009, pp. 1332 - 1336. http://dx.doi.org/10.1016/j.ssci.2009.02.002

${ }^{18}$ Nederlandse Mededingingsautoriteit, Netcode elektriciteit, 2013.

${ }^{19}$ TenneT, Quality and capacity plan 2010 - 2016. Technical report, 2009.

${ }^{20}$ Dobson, I., Carreras, B.A., Lynch, V.E., and Newman, D.E., "Complex systems analysis of series of blackouts: Cascading failure, critical points, and self-organization", Chaos, Vol. 17, 2007, pp. 1 - 13. http://dx.doi.org/10.1063/1.2737822

${ }^{21}$ Romero, J., "Blackouts illuminate India's power problems", IEEE Spectrum, Vol. 49, 2012, pp. $11-12$.

${ }^{22}$ Beniston, M, Stephenson, D.B., Christensen, O.B., Ferro, C.A.T., Frei, C., Goyette, S., Halsnaes, K., Holt, T., Jylha, K., Ko, B., Palutikof, J., Schoell, R., Semmler, T., and Woth, K., "Future extreme events in European climate: an exploration of regional climate model projections", Climatic Change, Vol. 81, 2007, pp. 71 - 95. http://dx.doi.org/10.1007/s10584006-9226-Z

${ }^{23}$ Dorland, C., Tol, R., and Palutikof, J., "Vulnerability of the Netherlands and Northwest Europe to storm damage under climate change", Climatic Change, Vol. 43, 1999, pp. 513 - 535. http://dx.doi.org/10.1023/A:1005492126814

${ }^{24}$ Katsman, C.A., Sterl, A., Beersma, J., van den Brink, H., Church, J., Hazeleger, W., Kopp, R., Kroon, D., Kwadijk, J., Lammersen, R., Lowe, J., Oppenheimer, M., Plag, H., Ridley, J., von Storch, J., Vaughan, D., Vellinga, P., Vermeersen, L., van de Wal, R., and Weisse, R., "Exploring high-end scenarios for local sea level rise to develop flood protection strategies for a low-lying delta - the Netherlands as an example", Climatic Change, Vol. 109, 2011, pp. 617 - 645. http://dx.doi.org/10.1007/s10584-011-0037-5 